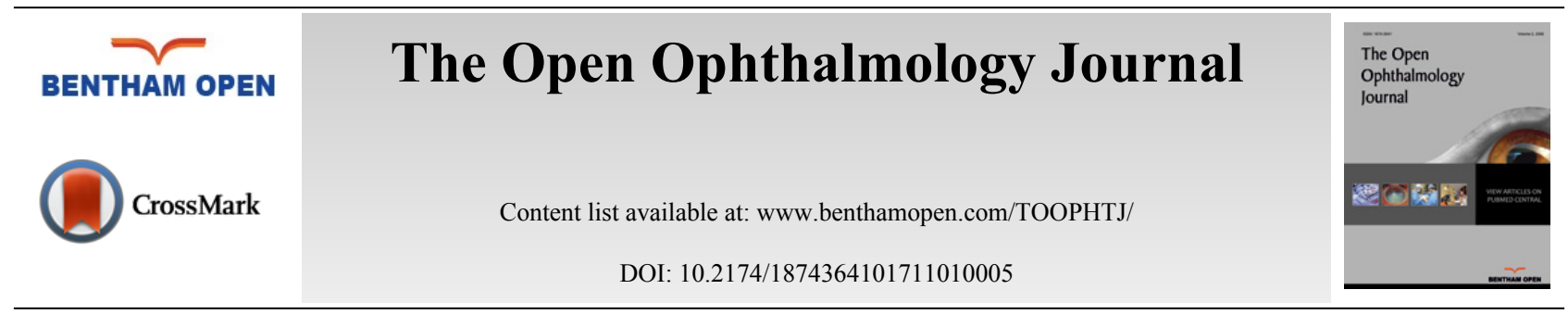

RESEARCH ARTICLE

\title{
Pars Plana Vitrectomy with Internal Limiting Membrane Peeling for Nontractional Diabetic Macular Edema
}

\author{
Jan Niklas Ulrich* \\ Department of Ophthalmology, University of North Carolina at Chapel Hill, United States
}

Received: September 09, 2016

Revised: December 22, 2016

Accepted: January 03, 2017

\begin{abstract}
:
Background:

Diabetes mellitus remains the leading cause of blindness among working age Americans with diabetic macular edema being the most common cause for moderate and severe vision loss.
\end{abstract}

\section{Objective:}

To investigate the anatomical and visual benefits of pars plana vitrectomy with inner limiting membrane peeling in patients with nontractional diabetic macular edema as well as correlation of integrity of outer retinal layers on spectral domain optical coherence tomography to visual outcomes.

\section{Methods:}

We retrospectively reviewed the charts of 42 diabetic patients that underwent vitrectomy with internal limiting membrane peeling for nontractional diabetic macula edema. The integrity of outer retinal layers was evaluated and preoperative central macular thickness and visual acuity were compared with data at 1 month, 3 months and 6 months postoperatively. The student t-test was used to compare the groups.

\section{Results:}

31 eyes were included. While no differences were seen at 1 and 3 months, there was significant improvement of both central macular thickness and visual acuity at the 6 months follow up visit compared to preoperatively $(357,427$ microns; $p=0.03$. 20/49, 20/82; $\mathrm{p}=0.03$ ). Patients with intact external limiting membrane and ellipsoid zone had better preoperative vision than patients with outer retinal layer irregularities $(20 / 54,20 / 100 ; \mathrm{p}=0.03)$ and greater visual gains postoperatively $(20 / 33, \mathrm{p}<0.001$ versus $20 / 81$; $\mathrm{p}=$ nonsignificant).

\section{Conclusion:}

Pars plana vitrectomy with internal limiting membrane peeling can improve retinal anatomy and visual acuity in patients with nontractional diabetic macular edema. Spectral domain optical coherence tomography may help identify patients with potential for visual improvement.

Keywords: Diabetic macular edema, Ellipsoid zone, Internal limiting membrane peeling, Pars plana vitrectomy.

\section{INTRODUCTION}

Diabetes mellitus remains the leading cause of blindness among working age Americans with diabetic macular edema (DME) being the most common cause for moderate and severe vision loss [1 - 3]. The use of anti-vascular endothelial grow factor (anti-vegf) medications has become the first line treatment for DME [4 - 9] with macular laser and steroids as adjuvant agents for non-responders [10 - 14]. Despite these improvements there is no standardized approach for the treatment of chronic or recurrent DME and repeated intraocular injections pose a significant burden on

\footnotetext{
* Address correspondence to this author at the Department of Ophthalmology, University of North Carolina at Chapel Hill, United States; Tel: (919) 966-5296; Fax: (919) 966-1908; E-mail: jnulrich@med.unc.edu
} 
patients, physicians and the healthcare system.

Pars plana vitrectomy (PPV) has been suggested as a potential alternative to intravitreal injections and macular laser. Multiple studies showed reduction in central macular thickness (CMT) and visual gains in patients with abnormalities of the vitreo-retinal interface [15 - 19]. More recently several papers evaluated the effects of PPV with or without internal limiting membrane (ILM) peeling in patients with nontractional DME and reported mixed effects. While some authors reported postoperative anatomic and visual improvements [20 - 23] others did not confirm gains in visual acuity [24 - 28].

In two publications the authors preoperatively examined the status of the outer retinal layers on spectral domain OCT (sdOCT) and reported visual gains after PPV with ILM peel in patients with preserved external limiting membrane and ellipsoid zone (EZ) retinal layers [29, 30].

Due to the heterogeneity of study designs it remains unclear to this day which patients would benefit from PPV with ILM peeling for DME.

In this study we evaluated if PPV with ILM peeling could reduce the CMT and improve visual acuity in patients with nontractional DME as well as the predictive value of preoperative sdOCT.

\section{MATERIAL AND METHODS}

We retrospectively reviewed the medical records of all consecutive patients undergoing PPV with ILM peeling for DME at our institution from 2012 to 2014.

We excluded patients with less than 6 month follow up or worse than 20/400 vision preoperatively, patients with abnormalities of the vitreo-retinal interface on sdOCT and patients who had received any treatment for DME within 3 months prior to vitrectomy. We also excluded patients who had received adjuvant intraoperative or postoperative steroid or anti-vegf injections.

All patients had undergone standard 25 -gauge vitrectomy with peribulbar anesthesia by a single surgeon. After induction of a posterior vitreous detachment, indocyanine green (ICG) assisted ILM peeling of an area of at least three disc diameters centered on the fovea was achieved.

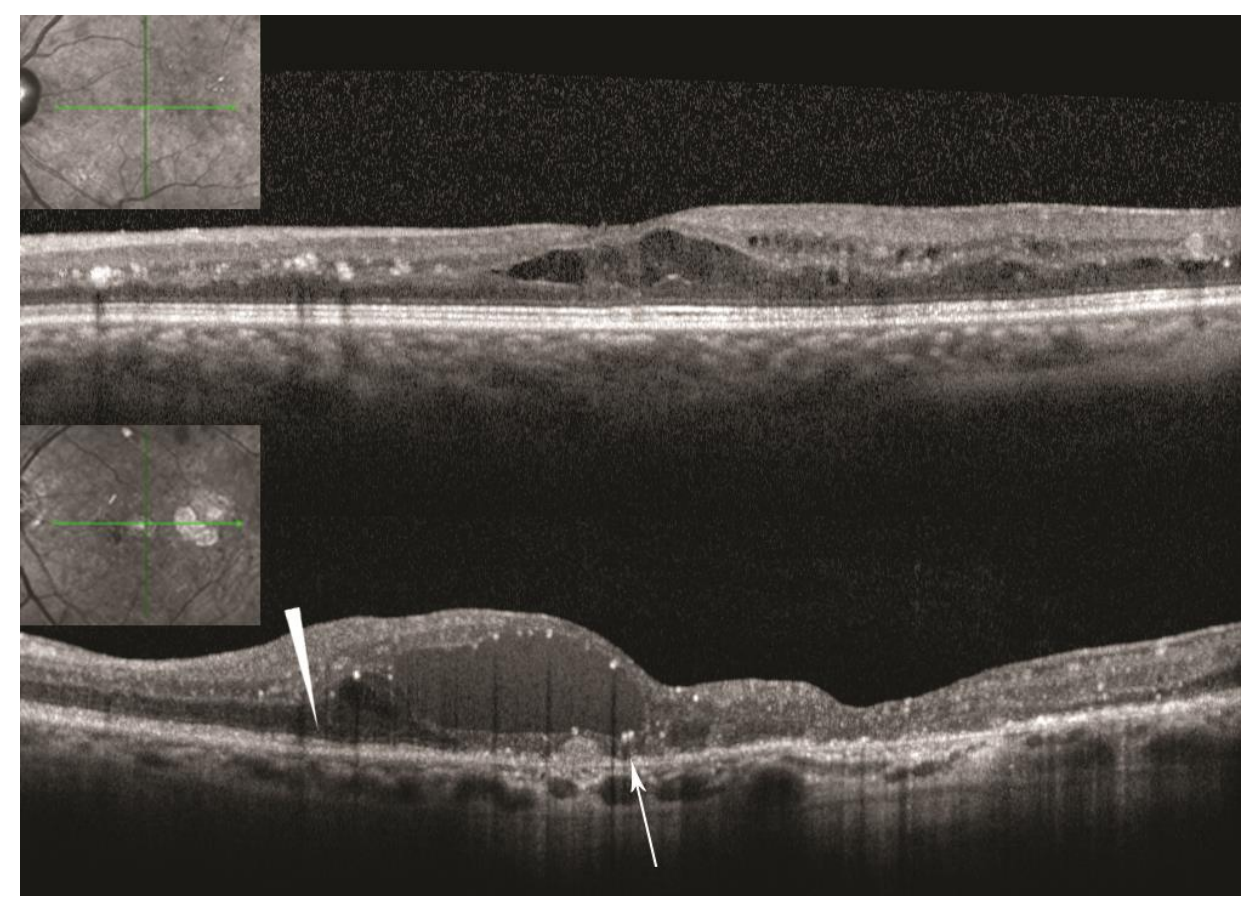

Fig. (1). Above: Patient with normal external limiting membrane (ELM) and ellipsoid zone (EZ),

Below: Normal ELM and EZ nasally (arrowhead). Absent ELM and irregular EZ in foveal area (arrow).

Patients had Heidelberg sdOCT images of the macula on the pre- and each postoperative visit (Heidelberg Engineering, Heidelberg, Germany). We evaluated OCT images for the presence of abnormalities of the vitreo-retinal 
interface and determined the status of the external limiting membrane (ELM) and ellipsoid zone (EZ) in the foveal area as preserved or disrupted/abnormal (Fig. 1).

Phakic status, prior number of intravitreal injections and focal/grid laser were recorded.

Visual acuity and central macular thickness were evaluated preoperatively as well as 1 month, 3 months and 6 months after the surgery. In a subgroup analysis patients with intact ELM/EZ were compared with patients with abnormal foveal anatomy and analyzed in regards to different outcome.

Pre- and postoperative data was compared using the student t-test. A p-value smaller than 0.05 was considered statistically significant.

All research adhered to the tenets of the Declaration of Helsinki and the Internal Review Board of our University had approved the study protocol.

\section{RESULTS}

We identified 42 eyes in the database and eventually included 31 eyes of 28 patients. Average age was 63 years, 17 out of 31 eyes $(55 \%)$ belonged to male patients (Table 1). The average preoperative CMT was 427 microns, mean visual acuity 20/82. 10 patients (32\%) had an intact ELM and ellipsoid zone in the foveal area.

Table 1. Baseline characteristics.

\begin{tabular}{|l|c|}
\hline & $\mathbf{N}=\mathbf{3 1}$ \\
\hline Age (mean in years) & 63 \\
\hline Male (\%) & $17(55)$ \\
\hline Number of prior injections (mean) & 5 \\
\hline Prior focal/grid laser (\%) & $19(61)$ \\
\hline Pseudophakia (\%) & $11(35)$ \\
\hline Intact ELM and EZ (\%) & $10(32)$ \\
\hline Preoperative CMT (mean/microns) & 427 \\
\hline Preoperative visual acuity (mean) & $20 / 82$ \\
\hline
\end{tabular}

ELM- External limiting membrane, EZ- ellipsoid zone.

At 1 and 3 months postoperatively, there was no significant change in either CMT $(431,390$ microns; $p=0.91,0.29)$ or visual acuity $(20 / 73,20 / 60 ; p=0.69,0.21)$. However at 6 months postoperatively the central macular thickness had significantly decreased (357 microns; $p=0.03)$ and the visual acuity was improved $(20 / 49 ; p=0.03$; Table 2). No patient had worsened visual acuity postoperatively and 10 patients (32\%) improved by three lines or more.

Table 2. Changes in central macular thickness and visual acuity over course of study.

\begin{tabular}{|l|c|c|c|c|c|}
\hline $\mathbf{N}=\mathbf{3 1}$ & Preop & 1 mos postop & 3 mos postop & 6 mos postop & P value (6-mos) \\
\hline CMT (mean/microns) & 427 & 431 & 390 & 357 & 0.03 \\
\hline VA & $20 / 82$ & $20 / 73$ & $20 / 60$ & $20 / 49$ & 0.03 \\
\hline
\end{tabular}

CMT- central macular thickness, VA- visual acuity.

Patients with intact ELM/EZ had statistically significant better visual acuity preoperatively compared to the patients with defects on OCT (20/54 vs 20/100; $p=0.03)$. Patients with intact foveal anatomy improved to $20 / 33$ at the last visit $(\mathrm{p}<0.009)$ with 6 out of 10 patients $(60 \%)$ gaining three or more lines of vision. Patients with defects in foveal anatomy improved to $20 / 81$ ( $p=$ non-significant) with only 4 patients $(20 \%)$ improving three or more lines of vision. There was no difference in foveal thickness between the groups with preserved and defective anatomy at any point in the study. (Table 3).

Table 3. Change in central macular thickness and visual acuity in patients with intact versus irregular outer retinal anatomy.

\begin{tabular}{|c|c|c|c|c|c|c|}
\hline & $\begin{array}{l}\text { Intact ELM/EZ Preop } \\
\qquad \mathrm{N}=10\end{array}$ & $\begin{array}{c}\text { Intact ELM/EZ } 6 \text { mos } \\
\text { postop } \mathrm{N}=10\end{array}$ & P value & $\begin{array}{l}\text { Irregular ELM/EZ Preop } \\
\qquad \mathrm{N}=21\end{array}$ & $\begin{array}{c}\text { Irregular ELM/EZ } 6 \text { mos } \\
\text { postop } \mathrm{N}=21\end{array}$ & P value \\
\hline CMT (mean/microns) & 407 & 368 & $\mathrm{~ns}$ & 453 & 350 & $\mathrm{~ns}$ \\
\hline VA & $20 / 54$ & $20 / 33$ & 0.009 & $20 / 100$ & $20 / 81$ & ns \\
\hline
\end{tabular}

ELM- External limiting membrane, EZ- ellipsoid zone, CMT- central macular thickness, VA- visual acuity, ns = non-significant. 


\section{DISCUSSION}

Our study was able to demonstrate a statistically significant improvement in visual acuity and decrease in foveal thickness six months after vitrectomy with ILM peel in patients with nontractional DME. The improvement in visual acuity was even more pronounced in patients with preserved foveal anatomy on sdOCT.

While the current literature appears to support vitrectomy for tractional DME [15 - 19], the benefit of PPV in patients with nontractional DME is much less clear. It is believed that vitrectomy can reduce DME by increasing the oxygenation in the vitreous cavity and removing proangiogenic factors like VEGF as well as cytokines and chemokines which promote a breakdown of the blood retinal barrier [31 - 33]. The role of ILM peeling during surgery remains unclear as well. In patients without obvious abnormalities of the vitreo-retina interface, peeling of the ILM can ensure that no residual vitreous is left behind and can reduce tangential traction [34, 35].

Kumagai et al. reported visual gains in two large series of patients with nontractional diabetic macular edema with or without ILM peeling. In these studies the macular anatomy was not assessed with sdOCT and all phakic patients underwent simultaneous cataract extraction which may have contributed to visual gains [36,37]. However, several studies were unable to demonstrate visual gains despite anatomical improvement [24 - 28].

Two authors recently reported an association between photoreceptor damage represented by disruption of the outer retina on sdOCT and visual acuity in patients DME. Chabblani's et al. group retrospectively studied 34 eyes with resistant DME and found pre-operative ELM integrity to be a better predictor for vision improvement than CMT or IS/OS junction integrity. While combining ELM integrity and preoperative CMT yielded the best predictive information, the addition of the IS/OS junction integrity was not beneficial. This study included patients with abnormalities of the vitreo-retinal interface (e.g. epiretinal membrane) which complicates a direct comparison to our study of nontractional DME [29]. Nishijama et al. reported on sdOCT findings and visual outcomes in a retrospective series of 32 eyes. Ten of these eyes were found to have what is described as "hyperreflective foci" in the outer retinal layers. While it remains unclear what exactly these foci represent, they appeared to be associated with damage to the IS/OS junction and worse visual outcome after vitrectomy [30].

In a recent retrospective study of 53 eyes, Browning et al. reported improved foveal thickness and visual acuity 12 months after vitrectomy for DME. The intactness of the EZ on sdOCT did not appear to be correlated with better postoperative vision. This study included patients with abnormalities of the vitreo-retinal interface, patients with proliferative diabetic retinopathy. Further, intravitreal steroids were injected in a majority of cases at the end of the surgery [38].

Due to significant heterogeneity among these studies including inclusion criteria, surgical technique and follow up, the visual benefit of PPV in patients with nontractional DME remains unclear.

Our study is limited by the small numbers and its retrospective nature. However, we were able to demonstrate visual and anatomical benefits in patients undergoing vitrectomy with ILM peeling for nontractional DME and suggest the integrity of the outer retina on sdOCT as possible predictor for visual potential.

Larger prospective studies may give additional insight into which patients will benefit the most from vitrectomy as well as the optimal time of surgical intervention.

\section{ETHICS APPROVAL AND CONSENT TO PARTICIPATE}

Not applicable.

\section{CONFLICT OF INTEREST}

The author confirms that this article content has no conflict of interest.

\section{ACKNOWLEDGEMENTS}

Declared none.

\section{REFERENCES}

[1] Klein R, Klein BE, Moss SE, Cruickshanks KJ. The wisconsin epidemiologic study of diabetic retinopathy. XV. The long-term incidence of macular edema. Ophthalmology 1995; 102(1): 7-16.

[http://dx.doi.org/10.1016/S0161-6420(95)31052-4] [PMID: 7831044] 
[2] Moss SE, Klein R, Klein BE, Cruickshanks KJ. Ten-year incidence of visual loss in a diabetic population. Ophthalmology 1994; 101(6): $1061-70$.

[http://dx.doi.org/10.1016/S0161-6420(94)31217-6] [PMID: 8008348]

[3] Klein BE. Overview of epidemiologic studies of diabetic retinopathy. Ophthalmic Epidemiol 2007; 14(4): 179-83. [http://dx.doi.org/10.1080/09286580701396720] [PMID: 17896294]

[4] Brown DM, Nguyen QD, Marcus DM, et al. Long-term outcomes of ranibizumab therapy for diabetic macular edema: the 36-month results from two phase III trials: RISE and RIDE. Ophthalmology 2013; 120(10): 2013-22. [http://dx.doi.org/10.1016/j.ophtha.2013.02.034] [PMID: 23706949]

[5] Do DV, Nguyen QD, Boyer D, et al. One-year outcomes of the da Vinci Study of VEGF Trap-Eye in eyes with diabetic macular edema. Ophthalmology 2012; 119(8): 1658-65.

[http://dx.doi.org/10.1016/j.ophtha.2012.02.010] [PMID: 22537617]

[6] Arevalo JF, Fromow-Guerra J, Quiroz-Mercado H, et al. Primary intravitreal bevacizumab (Avastin) for diabetic macular edema: results from the Pan-American Collaborative Retina Study Group at 6-month follow-up. Ophthalmology 2007; 114(4): 743-50. [http://dx.doi.org/10.1016/j.ophtha.2006.12.028] [PMID: 17398322]

[7] Sultan MB, Zhou D, Loftus J, Dombi T, Ice KS. A phase 2/3, multicenter, randomized, double-masked, 2-year trial of pegaptanib sodium for the treatment of diabetic macular edema. Ophthalmology 2011; 118(6): 1107-18. [http://dx.doi.org/10.1016/j.ophtha.2011.02.045] [PMID: 21529957]

[8] Michaelides M, Kaines A, Hamilton RD, et al. A prospective randomized trial of intravitreal bevacizumab or laser therapy in the management of diabetic macular edema (BOLT study) 12-month data: report 2. Ophthalmology 2010; 117(6): 1078-1086.e2. [http://dx.doi.org/10.1016/j.ophtha.2010.03.045] [PMID: 20416952]

[9] Elman MJ, Qin H, Aiello LP, et al. Intravitreal ranibizumab for diabetic macular edema with prompt versus deferred laser treatment: threeyear randomized trial results. Ophthalmology 2012; 119(11): 2312-8. [http://dx.doi.org/10.1016/j.ophtha.2012.08.022] [PMID: 22999634]

[10] Photocoagulation for diabetic macular edema. Early treatment diabetic retinopathy study report number 1 . Early Treatment Diabetic Retinopathy Study research group. Arch Ophthalmol 1985; 103(12): 1796-806. [http://dx.doi.org/10.1001/archopht.1985.01050120030015] [PMID: 2866759]

[11] Callanan DG, Gupta S, Boyer DS, et al. Dexamethasone intravitreal implant in combination with laser photocoagulation for the treatment of diffuse diabetic macular edema. Ophthalmology 2013; 120(9): 1843-51. [http://dx.doi.org/10.1016/j.ophtha.2013.02.018] [PMID: 23706947]

[12] Boyer DS, Yoon YH, Belfort R Jr, et al. Three-year, randomized, sham-controlled trial of dexamethasone intravitreal implant in patients with diabetic macular edema. Ophthalmology 2014; 121(10): 1904-14. [http://dx.doi.org/10.1016/j.ophtha.2014.04.024] [PMID: 24907062]

[13] Jonas JB, Kamppeter BA, Harder B, Vossmerbaeumer U, Sauder G, Spandau UH. Intravitreal triamcinolone acetonide for diabetic macular edema: a prospective, randomized study. J Ocul Pharmacol Ther 2006; 22(3): 200-7. [http://dx.doi.org/10.1089/jop.2006.22.200] [PMID: 16808682]

[14] Sanford M. Fluocinolone acetonide intravitreal implant (Iluvien ${ }^{\circledR}$ ): in diabetic macular oedema. Drugs 2013; 73(2): 187-93. [http://dx.doi.org/10.1007/s40265-013-0010-x] [PMID: 23335133]

[15] Lewis H, Abrams GW, Blumenkranz MS, Campo RV. Vitrectomy for diabetic macular traction and edema associated with posterior hyaloidal traction. Ophthalmology 1992; 99(5): 753-9.

[http://dx.doi.org/10.1016/S0161-6420(92)31901-3] [PMID: 1594222]

[16] van Effenterre G, Guyot-Argenton C, Guiberteau B, Hany I, Lacotte JL. Macular edema caused by contraction of the posterior hyaloid in diabetic retinopathy. Surgical treatment of a series of 22 cases. J Fr Ophtalmol 1993; 16(11): 602-10. [PMID: 8169307]

[17] Harbour JW, Smiddy WE, Flynn HW Jr, Rubsamen PE. Vitrectomy for diabetic macular edema associated with a thickened and taut posterior hyaloid membrane. Am J Ophthalmol 1996; 121(4): 405-13. [http://dx.doi.org/10.1016/S0002-9394(14)70437-4] [PMID: 8604734]

[18] Pendergast SD, Hassan TS, Williams GA, et al. Vitrectomy for diffuse diabetic macular edema associated with a taut premacular posterior hyaloid. Am J Ophthalmol 2000; 130(2): 178-86. [http://dx.doi.org/10.1016/S0002-9394(00)00472-4] [PMID: 11004291]

[19] Haller JA, Qin H, Apte RS, et al. Vitrectomy outcomes in eyes with diabetic macular edema and vitreomacular traction. Ophthalmology 2010; 117(6): 1087-1093.e3. [http://dx.doi.org/10.1016/j.ophtha.2009.10.040] [PMID: 20299105]

[20] Thomas D, Bunce C, Moorman C, Laidlaw DA. A randomised controlled feasibility trial of vitrectomy versus laser for diabetic macular oedema. Br J Ophthalmol 2005; 89(1): 81-6. [http://dx.doi.org/10.1136/bjo.2004.044966] [PMID: 15615752]

[21] Bahadir M, Ertan A, Mertoğlu O. Visual acuity comparison of vitrectomy with and without internal limiting membrane removal in the treatment of diabetic macular edema. Int Ophthalmol 2005; 26(1-2): 3-8. 
[http://dx.doi.org/10.1007/s10792-006-0008-4] [PMID: 16786177]

[22] Bardak Y, Cekiç O, Tiğ SU. Comparison of ICG-assisted ILM peeling and triamcinolone-assisted posterior vitreous removal in diffuse diabetic macular oedema. Eye (Lond) 2006; 20(12): 1357-9.

[http://dx.doi.org/10.1038/sj.eye.6702152] [PMID: 16294204]

[23] Doi N, Sakamoto T, Sonoda Y, et al. Comparative study of vitrectomy versus intravitreous triamcinolone for diabetic macular edema on randomized paired-eyes. Graefes Arch Clin Exp Ophthalmol 2012; 250(1): 71-8. [http://dx.doi.org/10.1007/s00417-011-1777-7] [PMID: 21853229]

[24] Figueroa MS, Contreras I, Noval S. Surgical and anatomical outcomes of pars plana vitrectomy for diffuse nontractional diabetic macular edema. Retina 2008; 28(3): 420-6. [http://dx.doi.org/10.1097/IAE.0b013e318159e7d2] [PMID: 18327133]

[25] Hoerauf H, Brüggemann A, Muecke M, et al. Pars plana vitrectomy for diabetic macular edema. Internal limiting membrane delamination vs posterior hyaloid removal. A prospective randomized trial. Graefes Arch Clin Exp Ophthalmol 2011; 249(7): 997-1008. [http://dx.doi.org/10.1007/s00417-010-1610-8] [PMID: 21243370]

[26] Kumar A, Sinha S, Azad R, Sharma YR, Vohra R. Comparative evaluation of vitrectomy and dye-enhanced ILM peel with grid laser in diffuse diabetic macular edema. Graefes Arch Clin Exp Ophthalmol 2007; 245(3): 360-8. [http://dx.doi.org/10.1007/s00417-006-0456-6] [PMID: 17093998]

[27] Patel JI, Hykin PG, Schadt M, et al. Diabetic macular oedema: pilot randomised trial of pars plana vitrectomy vs macular argon photocoagulation. Eye (Lond) 2006; 20(8): 873-81. [http://dx.doi.org/10.1038/sj.eye.6702012] [PMID: 16052254]

[28] Liu DC, Wu H, Yang HQ. Clinical observation of vitrectomy for treatment of diffuse nontraditional diabetic macular edema. Zhonghua Yan Ke Za Zhi 2011; 47(6): 492-6. [PMID: 21914262]

[29] Chhablani JK, Kim JS, Cheng L, Kozak I, Freeman W. External limiting membrane as a predictor of visual improvement in diabetic macular edema after pars plana vitrectomy. Graefes Arch Clin Exp Ophthalmol 2012; 250(10): 1415-20. [http://dx.doi.org/10.1007/s00417-012-1968-x] [PMID: 22354371]

[30] Nishijima K, Murakami T, Hirashima T, et al. Hyperreflective foci in outer retina predictive of photoreceptor damage and poor vision after vitrectomy for diabetic macular edema. Retina 2014; 34(4): 732-40. [http://dx.doi.org/10.1097/IAE.0000000000000005] [PMID: 24177189]

[31] Stefansson E, Landers MB III, Wolbarsht ML. Increased retinal oxygen supply following pan-retinal photocoagulation and vitrectomy and lensectomy. Trans Am Ophthalmol Soc 1981; 79: 307-34.

[PMID: 7200671]

[32] Holekamp NM, Shui YB, Beebe DC. Vitrectomy surgery increases oxygen exposure to the lens: a possible mechanism for nuclear cataract formation. Am J Ophthalmol 2005; 139(2): 302-10. [http://dx.doi.org/10.1016/j.ajo.2004.09.046] [PMID: 15733992]

[33] Park JH, Woo SJ, Ha YJ, Yu HG. Effect of vitrectomy on macular microcirculation in patients with diffuse diabetic macular edema. Graefes Arch Clin Exp Ophthalmol 2009; 247(8): 1009-17. [http://dx.doi.org/10.1007/s00417-009-1062-1] [PMID: 19294405]

[34] Gandorfer A, Messmer EM, Ulbig MW, Kampik A. Resolution of diabetic macular edema after surgical removal of the posterior hyaloid and the inner limiting membrane. Retina 2000; 20(2): 126-33. [http://dx.doi.org/10.1097/00006982-200002000-00004] [PMID: 10783944]

[35] Rice S, Madreperla SA, McCuen B. Internal limiting membrane removal in surgery for full thickness macular holes Macular Hole Pathogenesis, Diagnosis and Treatment. 2nd ed. Boston: Butterworth Heinemann 1998; pp. 125-46.

[36] Kumagai K, Hangai M, Ogino N, Larson E. Effect of internal limiting membrane peeling on long-term visual outcomes for diabetic macular edema. Retina 2015; 35(7): 1422-8. [http://dx.doi.org/10.1097/IAE.0000000000000497] [PMID: 26102439]

[37] Kumagai K, Furukawa M, Ogino N, Larson E, Iwaki M, Tachi N. Long-term follow-up of vitrectomy for diffuse nontractional diabetic macular edema. Retina 2009; 29(4): 464-72.

[http://dx.doi.org/10.1097/IAE.0b013e31819c632f]

[38] Browning DJ, Lee C, Stewart MW, Landers MB III. Vitrectomy for center-involved diabetic macular edema. Clin Ophthalmol 2016; 10: $735-42$.

[http://dx.doi.org/10.2147/OPTH.S104906] [PMID: 27175056]

(C) Jan Niklas Ulrich; Licensee Bentham Open

This is an open access article licensed under the terms of the Creative Commons Attribution-Non-Commercial 4.0 International Public License (CC BY-NC 4.0) (https://creativecommons.org/licenses/by-nc/4.0/legalcode), which permits unrestricted, non-commercial use, distribution and reproduction in any medium, provided the work is properly cited. 